\title{
Aggregation Pheromone of the African Rhinoceros Beetle, Oryctes monoceros (Olivier) (Coleoptera: Scarabaeidae)
}

\author{
G. Gries and R. Gries
}

Department of Biological Sciences, Simon Fraser University, Burnaby, B.C., Canada V 5 A 1 S 6

\author{
A. L. Perez, A. C. Oehlschlager, L. M. Gonzales and H. D. Pierce, Jr. \\ Department of Chemistry, Simon Fraser University, Burnaby, B.C., Canada V 5 A 1S 6
}

\begin{abstract}
M. Zebeyou and B. Kouame
Institut des Forêts (IDEFOR), Department des Plantes Oléagineuxes, Station Principale de La Me, 13 BP. 989 Abidjan 13, Côte d'Ivoire
\end{abstract}

Z. Naturforsch. 49c, 363-366 (1994); received October 4, 1993/March 4, 1994

Coleoptera, Oryctes monoceros, African Rhinoceros Beetle, Aggregation Pheromone,

Ethyl 4-Methyloctanoate

Ethyl 4-methyloctanoate is a male-produced aggregation pheromone of the African rhinoceros beetle, Oryctes monoceros (Olivier). It was identified by coupled gas chromatographicelectroantennographic detection (GC-EAD) and coupled GC-mass spectrometry (MS) of Porapak Q-trapped male-produced volatiles. Natural and synthetic ethyl 4-methyloctanoate elicited comparable antennal responses. In a field experiment (La Me Research Station, Côte d'Ivoire), synthetic ethyl 4-methyloctanoate released at $30 \mathrm{mg} /$ day attracted both male and female Oryctes, whereas the known, non-beetle-produced attractant, ethyl chrysanthemate, did not attract any Oryctes. Upon improvement of trap design and placement, and the identification of synergistic (plant) volatiles, pheromone-based mass trapping may become an alternative and/or additional strategy to manage $O$. monoceros, one of the most destructive pests of commercial coconut, oil, and date palms in Africa.

\section{Introduction}

The African rhinoceros beetle, Oryctes monoceros (Olivier) (Coleoptera: Scarabaeidae), is one of the most destructive pests of commercial coconut, oil and date palm in Africa (Hill, 1983). While the larvae develop in decomposing organic matter, adults feed inside of unopened fronds and meristem of palms. Beetle attacks kill young palms, provide entry holes for lethal diseases and other destructive insects, damage inflorescences and reduce photosynthetically active foliage, thereby diminishing revenue of oil and coconut production (Mariau et al., 1981). Introduction of pathogenic baculovirus, Rhabdionvirus oryctes, suppressed populations of the rhinoceros beetle, $O$. rhinoceros, in parts of Asia (Bedford, 1986; Zelazny and Alfiler, 1987, 1991; Young, 1986) but did not effect O. monoceros in Africa (Julia and Mariau, 1976a).

Reprint requests to Dr. G. Gries.

Telefax: 604-291-3496.

0939-5075/94/0500-0363 \$03.00

(C) Verlag der Zeitschrift für Naturforschung,

D-72072 Tübingen
O. monoceros is currently controlled by silvicultural methods (Hinckley, 1973; Ouvrier, 1980) and removal of adults from young palms and larvae from decomposing logs. Pheromone-based trapping would be an ideal alternative and/or additional strategy to manage rhinoceros beetles in Africa. We report the identification of a male-produced aggregation pheromone in $O$. monoceros.

\section{Materials and Methods}

Male (15) and female (18) O. monoceros were collected in oil palm plantations $40-50 \mathrm{~km}$ northeast of Abidjan, Côte d'Ivoire, and placed together in a modified Nalgene desiccator (Oehlschlager et al., 1992). An aspirator-driven charcoal-filtered airstream was maintained through the desiccator for 5 days, collecting male- and femalereleased volatiles on Porapak Q. In a second experiment, 11 females and 13 males were aerated separately for 7 days. Volatiles were eluted from Porapak Q with pentane, concentrated by distillation and subjected to gas chromatographic (GC) analysis with flame ionization (FID) and electroantennographic detection (EAD) (Arn et al., 
1975), employing a Hewlett-Packard (HP) 5890 A gas chromatograph equipped with a $30 \mathrm{~m} \times 0.25$ mm ID SP-1000-coated, fused silica column (Supelco Inc., Bellefonte, PA 16823). Coupled GC-mass spectrometry (MS) was conducted using a HP 5985 B GC-MS fitted with the same column.

The candidate pheromone ethyl 4-methyloctanoate was synthesized by conjugate addition of an organocuprate to ethyl acrylate (Corey and Boaz, 1985; Matsuzawa et al., 1989). This was prepared by addition of $\mathrm{CuCN}(10 \mathrm{~mol} \%)$ to 2-hexylmagnesium bromide in $\mathrm{THF}$ at $-40^{\circ} \mathrm{C}$. After stirring $30 \mathrm{~min}$, the solution was cooled to $-78^{\circ} \mathrm{C}$, and trimethylchlorosilane and HMPA (2.4 equiv. each) and ethyl acrylate ( 2 equiv.) in THF were added dropwise via cannula. After $2 \mathrm{~h}$, work up of the reaction followed by column chromatography gave ethyl 4-methyloctanoate ( $95 \%$ pure) in $56 \%$ yield.

This compound was tested 8-17 May 1993 in 3- to 4-year-old oil palm plantations at the La Me Research Station, Côte d'Ivoire. 151 Plastic buckets (Oehlschlager et al., 1993) 1-2 m apart from palms were employed as pitfall traps (side entrance holes at ground level) in randomized complete blocks with traps at $27 \mathrm{~m}$ intervals and blocks 27-500 m apart. A 4-treatment, 8-replicate experiment tested attraction of the known, nonbeetle-produced attractant ethyl chrysanthemate (EC) (Maddison et al., 1973; Julia and Mariau, 1976b) (30 mg/day, @ $25^{\circ} \mathrm{C}$ ) and the candidate pheromone ethyl 4-methyloctanoate released at 3 doses $\left(0.3,3\right.$, or $30 \mathrm{mg} / \mathrm{day}$, @25 $\left.{ }^{\circ} \mathrm{C}\right)$. Petrolatum (Anachemia, Rouses Point, N.Y. 12979) on the inner bucket surface below side entrances and a wet sponge treated with insecticidal Evisect "S" (3\% thiocylam-hydrogenoxalate in water) at the bottom of the bucket, assured retainment of captured beetles. Weakly effective insecticide and petrolatum were probably unnecessary because captured beetles could not climb the smooth plastic bucket.

\section{Results and Discussion}

GC and GC-EAD analyses of Porapak Qtrapped volatiles obtained from aerations of either Oryctes males, females or both sexes combined revealed two male specific compounds (Fig. 1), of which the early eluting volatile elicited responses

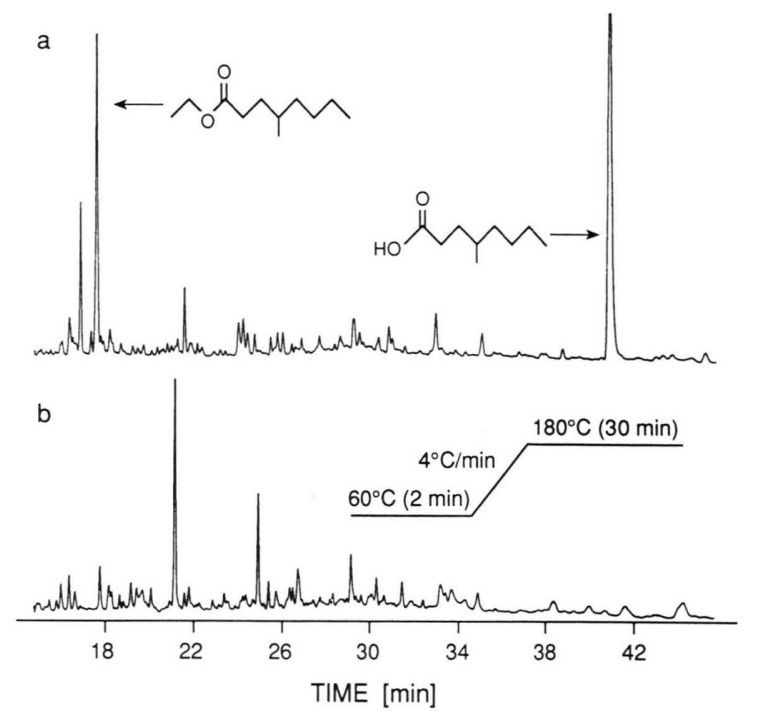

Fig. 1. Gas chromatograms of volatiles from male $(n=13)$ (a) and female $(n=11)$ (b) O. monoceros maintained in aeration chambers for $168 \mathrm{~h}$ without provision of food. Chromatography: Hewlett-Packard $5830 \mathrm{~A}$ equipped with a glass capillary column $(30 \mathrm{~m} \times 0.5 \mathrm{~mm}$ ID) coated with SP-1000.

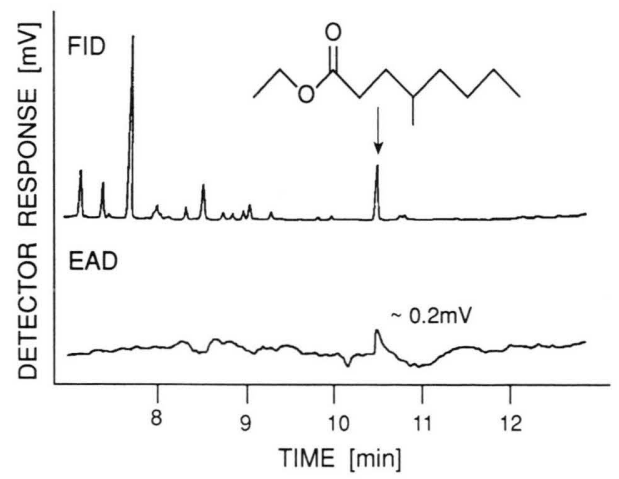

Fig. 2. Representative recording $(n=9)$ of FID and EAD responses to volatiles obtained from male and female $O$. monoceros. The antennal recording was carried out with an antenna of a female beetle. Chromatography: Hewlett-Packard (HP) $5890 \mathrm{~A}$ gas chromatograph (GC) equipped with a fused silica column $(30 \mathrm{~m} \times 0.25 \mathrm{~mm}$ ID) coated with SP-1000; $1 \mathrm{~min}$ at $70{ }^{\circ} \mathrm{C}, 10^{\circ} \mathrm{C} / \mathrm{min}$ to $180^{\circ} \mathrm{C}$.

from male and female antennae (Fig. 2). This male-specific compound was not detected by FID, GC-MS or EAD in female-produced volatiles (Fig. 1). GC-MS of the antennally active compound (Fig. 3) indicated an ethyl ester ( $\mathrm{MW}=$ 


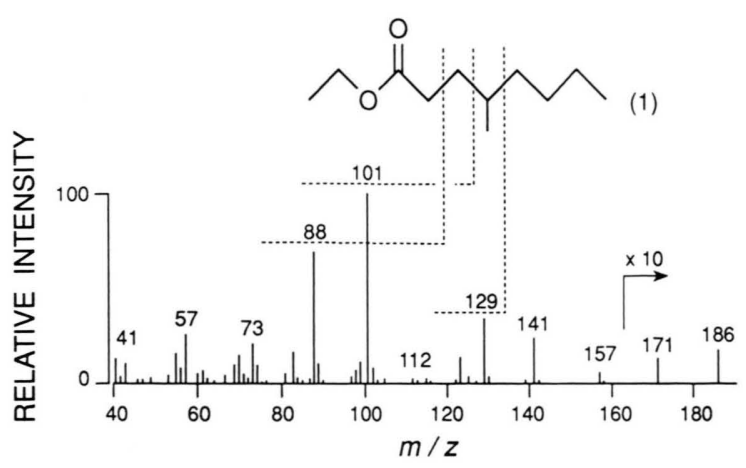

Fig. 3. Electron impact $(70 \mathrm{eV})$ mass spectrum of ethyl 4-methyloctanoate. Chromatography: Hewlett-Packard 5985 B GC-mass spectrometer; column and temperature program as in Fig. 2.

186) (Jennings and Shibamoto, 1980) with a retention index lower than that of isomeric, straight chain ethyl nonanoate. Based on the increased intensity of the $\mathrm{m} / \mathrm{z} 101$ and $\mathrm{m} / \mathrm{z} 129$ fragmentation ions (Fig. 3), we hypothesized that the compound was ethyl 4-methyloctanoate. Identical retention and mass spectrometric characteristics as well as comparable antennal activity of synthetic and male-produced ethyl 4-methyloctanoate confirmed this structural assignment.

In a field experiment, ethyl 4-methyloctanoate released at $30 \mathrm{mg} /$ day attracted 6 males and $5 \mathrm{fe}$ males in 9 days, whereas the known attractant ethyl chrysanthemate at $30 \mathrm{mg} /$ day did not attract any Oryctes. Lower release rates of the pheromone were not attractive.

In assessing absolute trap captures, low relative abundance of these very large insects must be taken into account. In 1992 e.g., weekly removal of Oryctes from palms had revealed $\sim 9$ adults per hectare per month in these plantations (M. Zebeyou, unpublished). Had the pheromone experiment been conducted in beetle-preferred coconut rather than oil palm stands, and not prior to but in the middle of the raining season during which Oryctes is more abundant (Mariau et al., 1981), trap catches probably would have been higher. However, capture of 11 Oryctes to ethyl 4-methyloctanoate versus none to the known attractant EC clearly indicates superior attraction of the aggregation pheromone. Addition of as yet unknown plant volatiles will likely enhance attraction of the aggregation pheromone. Palm weevil aggregation pheromones in the Rhynchophorinae, e.g., are hardly attractive by themselves and require the presence of synergistic plant volatiles (Gries et al., 1993; Hallett et al., 1993; Weissling et al., 1994). Capture rates of Oryctes might also be improved by refining and optimizing pheromone formulation, and trap design and placement.

Molecular structures of scarab beetle pheromones are diverse. $(R, Z)$-5-(1-Decenyl)dihydro$2(3 \mathrm{H})$-furanone (Tumlinson et al., 1977), methyl (Z)-5-tetradecenoate (Tamaki et al., 1985) and $(R, Z)$-5-(-)-(oct-1-enyl)oxacyclopentan-2-one (Leal, 1991) are female-produced sex pheromones of Japanese beetle, Popillia japonica, soybean beetle, Anomala rufocuprea, and cupreous chafer beetle, A. cuprea, respectively. Females of the grass grab beetle, Costelytra zealandica, utilize phenol to attract males (Henzell and Lowe, 1970), whereas males of the dung beetle, Kheper lamarcki, release hexadecanoic acid, 2,6-dimethyl5-heptenoic acid and (E)-nerolidol along with a polypeptide pheromone carrier (Burger et al., 1983, 1990). Although only 5 insects were caught in a field experiment, Leal et al. (1992) provide evidence that female large black chafer, Holotrichia paralellela, attract males with L-isoleucine methyl ester, a unique amino acid derived sex pheromone.

Unlike these previously identified sex pheromones in the Scarabaeidae, ethyl 4-methyloctanoate is a novel aggregation pheromone for which we propose the trivial name "oryctelure". Future research targets the development and implementation of oryctelure for control of $O$. monoceros in commercial oil, coconut, and date palms in Africa.

\section{Acknowledgements}

We thank G. Owen for mass spectrometry, $\mathrm{N}$. Mouhoussine of the University of Ouagadougou, Burkina Faso, for facilitating initial field collection of $O$. monoceros, and the University of Costa Rica for a fellowship to A. L. P. The research was supported by an NSERC research grant to A. C. O. 
Arn H., Städtler E. and Rauscher S. (1975), The electroantennographic detector - a selective and sensitive tool in the gas chromatographic analysis of insect sex pheromones. Z. Naturforsch. 30 c, 722-725.

Bedford G. O. (1986), Biological control of the rhinoceros beetle (Oryctes rhinoceros) in the South Pacific by baculovirus. Agriculture, Ecosystems and Environment 15, 141-147.

Burger B. V., Munro Z., Röth M., Spier H. S. C., Truter V., Tribe G. D. and Crewe R. M. C. (1983), Composition of the heterogeneous sex attracting secretion of the dung beetle, Kheper lamarcki. Z. Naturforsch. 38 c, $848-855$.

Burger B. V., Munro Z. and Brandt W. F. (1990), Pheromones of the Scarabaeinae, II. Composition of the pheromone disseminating carrier material secreted by male dung beetles of the genus Kheper. Z. Naturforsch. 45 c, $863-872$.

Corey E. J. and Boaz N. W. (1985), The reaction of combined organocuprate-chlorotrimethyl silane reagents with conjugated carbonyl compounds. Tetrahedron Lett. 26, 6019-6022.

Gries G., Gries R., Perez A. L., Oehlschlager A. C., Gonzales L. M., Pierce H. D., Jr., Kouda-Bonafos M., Zebeyou M. and Nanou N. (1993), Aggregation pheromone of the African palm weevil, Rhynchophorus phoenicis. Naturwissenschaften 80, 90-91.

Hallett R. H., Gries G., Gries R., Borden J. H., Czyzewska E., Oehlschlager A. C., Pierce H. D., Jr., Angerilli N. P. D. and Rauf A. (1993), Aggregation pheromone of two Asian palm weevils, Rhynchophorus ferrugineus and $R$. vulneratus. Naturwissenschaften $\mathbf{8 0}$, $328-331$.

Henzell R. F. and Lowe M. D. (1970), Sex attractant of the grass grub beetle. Science 168, 1005-1006.

Hill D. S. (1983), Agricultural pests of the tropics and their control, 776 pp., Cambridge University Press.

Hinckley A. D. (1973), Ecology of the coconut rhinoceros beetle Oryctes rhinoceros (L.) (Coleoptera: Dynastidae). Biotropica 5, 111-116.

Jennings W. and Shibamoto T. (1980), Qualitative analysis of flavor and fragrance volatiles by glass capillary gas chromatography, p. 472, Academic Press, New York.

Julia J. F. and Mariau D. (1976a), Research on Oryctes monoceros $\mathrm{Ol}$. in the Ivory Coast. II. Trial of biological control by virus Rhabdionvirus oryctes. Oleagineux 31, 113-117.

Julia J. F. and Mariau D. (1976b), Research on Oryctes monoceros in Ivory Coast. III. Olfactory trapping with ethyl chrysanthemate. Oleagineux 31, 263-272.

Leal W. S. (1991), (R,Z)-5-(-)-(Oct-1-enyl)oxacyclopentan-2-one, the sex pheromone of the scarab beetle, Anomala cuprea. Naturwissenschaften 78, $521-523$.
Leal W. S., Matsuyama S., Kuwahara Y., Wakamura S. and Hasegawa M. (1992), An amino acid derivative as the sex pheromone of a scarab beetle. Naturwissenschaften 79, 184-185.

Maddison P. A., Beroza M. and McGovern T. P. (1973), Ethyl chrysanthemumate as an attractant for the coconut rhinoceros beetle. J. Econ. Entomol. 66, $591-592$.

Mariau D., Desmier de Chenon R., Julia J. F. and Philippe R. (1981), Oil palm insect pests and their enemies in Africa. Oleagineux 36, 170-217.

Matsuzawa S., Horiguchi Y., Nakamura E. and Kuwajima I. (1989), Chlorosilane-accelerated conjugate addition of catalytic and stoichiometric organo copper reagents. Tetrahedron $\mathbf{4 5}, 349-362$.

Oehlschlager A. C., Pierce H. D., Jr., Morgan B., Wimalaratne P. D. C., Slessor K. N., King G. G. S., Gries G., Gries R., Borden J. H., Jiron L. F., Chinchilla C. M. and Mexzan R. G. (1992), Chirality and field activity of rhynchophorol, the aggregation pheromone of the American palm weevil. Naturwissenschaften 79, $134-135$.

Oehlschlager A. C., Chinchilla C. M., Gonzales L. M., Jiron L. F., Mexzon R. and Morgan B. (1993), Development of a pheromone-based trapping system for Rhynchophorus palmarum (Coleoptera: Curculionidae). J. Econ. Entomol. 86, 1381-1392.

Ouvrier M. (1980), Agronomic value of alternate windrowing in industrial coconut plantations. Oleagineux 35, $347-351$.

Tamaki Y., Sugie H. and Noguchi H. (1985), Methyl (Z)-5-tetradecenoate: sex attractant pheromone of the soybean beetle, Anomala rufocuprea Motschulsky (Coleoptera: Scarabaeidae). App. Ent. Zool. 20, 359-361.

Tumlinson J. H., Klein M. G., Doolittle R. E., Ladd T. L. and Proveaux A. T. (1977), Identification of the female japanese beetle sex pheromone: Inhibition of male response by an enantiomer. Science 197, $789-792$.

Weissling T. J., Giblin-Davis R. M., Gries G., Gries R., Perez A. L., Pierce H. D., Jr. and Oehlschlager A. C. (1994), Aggregration pheromone of the Palmetto Weevil, Rhynchophorus cruentatus (F.) (Coleoptera: Curculionidae). J. Chem. Ecol. 20, $505-515$.

Young E. C. (1986), The rhinoceros beetle project: history and review of the research programme. Agriculture, Ecosystems and Environment 15, 149-166.

Zelazny B. and Alfiler A. R. (1987), Ecological methods for adult populations of Oryctes rhinoceros (Coleoptera: Scarabaeidae). Ecol. Entomol. 12, 227-238.

Zelazny B. and Alfiler A. R. (1991), Ecology of baculovirus-infested and healthy adults of Oryctes rhinoceros (Coleoptera: Scarabaeidae) on coconut palms in the Philippines. Ecol. Entomol. 16, 253-259. 